\title{
Analyzing the impact of agricultural donor aid on food security in West Africa
}

\author{
Lansana Alhassan Sesay*, Theresia Gunawan, Rulyusa Pratikto, Pius Sugeng \\ Prasetyo, and Indraswari \\ Faculty of Social Sciences and Political Sciences, Universitas Katolik Parahyangan, Bandung 40141, \\ West Java, Indonesia
}

\begin{abstract}
Despite the abundance of agricultural donor aid to the lessdeveloped nations, especially in West African countries, little is known regarding its role in enhancing food security. This study argues that the flow of aid to the productive sector would have a sustainable impact since it has a multiplier effect on the recipient countries by enhancing productivity in the agricultural sector. Therefore, by filling this gap, the research aims to analyze the impact of agricultural donor aid on food security in 16 West African countries between 2009-2018. The study adopted quantitative crosscountry panel data and utilized the Two-Stage Least Square Regression model (2SLS) to examine to what extent agricultural aid has impacted food security in the sub-region. This method was adopted to address the endogeneity problems in this research model specification, where it is assumed that there is a reverse causality between donor aid and food security. The findings indicate that agricultural aid has impacts on food accessibility, and utilization in West Africa. This impact is based on good governance and the institutional qualities of recipient countries.
\end{abstract}

\section{Introduction}

Food insecurity phenomena remain the main unrelenting and implacable problems affecting the global population and stunting many nations' development, especially emerging economies in West Africa[1,2]. The negative implications of food insecurity worldwide remain the main concern for determining the United Nations' global policy agenda on sustainable development, intending to address global hunger and enhance sustainable food security for everyone[3,4]. The past decade has shown extensive academic research and policy strategies on the global food security status [2].

However, this has not been fully translated into alleviating and addressing the global challenges as expected, which makes the path to the 2030 vision very rough and highly questionable as policymakers are currently losing track of the problem due to the various global challenges: such as population growth, environmental issues, conflict, and climate change, followed by the global economic recessions and financial crisis which continue to trigger the global food price inflation[5-7]. The decline in global food insecurity from $27.6 \%$ in 1992 to $20 \%$ in 2014 has shown progress in achieving the policy aspiration [6].

\footnotetext{
* Corresponding author: lanslot24@email.com
} 
The recent 2019 report published by the Food and Agriculture Organisation stated that we are in the era of abundant food availability where supply exceeds demand [7, 8]. Yet, even at the point of abundant food availability as of 2019, 820 million people globally are food insecure, while 257 million Africans suffer from chronic hunger and undernourishment. Additionally, $45 \%$ of African children died each year due to a lack of nutritious and safe food. West African countries find themselves on the edge of food insecurity challenges. The report stated that the sub-region frequently experienced a progressive increase in chronic undernourishment. The data indicated a rise from 38.7 million people in 2014 to 56.1 million in 2018. On the other hand, severe food insecurity steadily rose from 44.4 million in 2014 to 67.2 million in 2018 [8]. These negative consequences of food insecurity continue to cripple the lives and economies of ECOWAS countries.

Addressing this trajectory, policymakers and development partners generally agree that the agricultural sector plays a vital role as a blueprint to food insecurity and as the primary approach to eradicate poverty [3,9]. Various academic evidence has indicated that growth in the agricultural sector is more effective in addressing food security and decreasing national and rural poverty in developing countries than in any other economic sector [10]. The early analysis by [11] concluded that any $1 \%$ increase in GDP in the agrarian productivity sector decreases the poverty rate by five times more than the $1 \%$ increase in the GDP from any other sector in the national economy. The Africa Development Bank report published in 2016 stated that more than half of the population in the rural areas in Africa depends on agricultural production for their well-being and accounts for more than $60 \%$ of the employment opportunity for women and youth, especially in the West Africa sub-region[12].

The following analysis by $[9,13]$ states that increasing domestic productivity at the national level requires proactive policies on agricultural innovation, modernization, foreign direct investment, domestic resources mobilization, and increased government fiscal spending to enhance sustainable food production in West Africa. Consequently, there are critical challenges for revenue mobilization in most countries classified under the lowincome group. For example, Liberia, Guinea, Gambia, Sierra Leone, and Togo cannot meet revenue mobilization to support most national development agendas.

Therefore, in a collaborative effort to improve the agricultural sector and address the food insecurity challenges in West Africa, the development partners have frequently conveyed a vital proactive global policy on official development assistance (ODA) through the international partnership agreement. This policy aims to provide financial aid to address the socio-economic challenges, particularly food insecurity and poverty in the sub-region $[1,14]$. These policies aim to improve individual countries' economic growth and development and strengthen bilateral and multilateral ties among countries and organizations. For instance, after the 2007/08 global food price crisis that negatively affected most West African countries, world leaders proposed to fund USD 22 billion in 2009 towards agriculture and food security projects in developing countries $[1,15]$.

Despite the positive role of donor aid and agriculture has in influencing food security in the sub-region, the study found that its impact on improving sustainable food security in West Africa has not been sufficiently investigated. Therefore, to fill this literature gap, the research aims to analyze the impact of agricultural aid on food security. In addressing this general objective, the study seeks to answer the question to what extent agriculture aid has impacted food security indicators in West Africa. This current study contributes to the existing literature by updating academic scholars and policymakers on the relationship between aid and the four-dimension food security by applying an annual pane data of 16 countries in West Africa from 2009 to 2018 . The findings provide a general conclusion and recommendation on the link between aid and four dimensions. The rest of the research paper follows the structures below; section two reviewed previous studies, followed by section three with 
variables description and analysis methods, while section four presents the result, discussion, and conclusion.

\section{Conceptual and theoretical review of related studies}

In this section, the research review and describes the recent relevant literature related to development aid to agriculture and food security indicators.

\subsection{Food insecurity}

The determination of food insecurity is complicated in several interrelated factors. Food insecurity is complex in assessment and multidimensional in concepts. Examining it from the macroeconomic or microeconomic level requires a comprehensive understanding of its different dimensions and indicators [16, 17]. Since its evolution, defining or describing, and measuring food insecurity has become a critical challenge. Nevertheless, the most cited and acknowledged description stated that food security at any level exists in the flowing precondition.

First, when enough food is available for everyone. Second, when an individual has both economic and physical access to the required quality and quantity. Third, when food refers to utilities in proper condition to obtain the most appropriate diet for a healthy life and finally, without the threat of future instability or shortages $[16,18,19]$. To build on the conceptual definition, the FAO developed four-dimension availability, accessibility, utilization, and stability; each of the dimensions provides a set of estimated indicators that can be used to measure and determine the level of food insecurity at any level [20, 21].

\subsection{Food security dimensions}

The food availability is directly connected to the supply side of the food chain system, which can be achieved through sustainable domestic agricultural production, commercial food imports, and humanitarian food aid. Considerable empirical evidence [3, 22] has described the farming sector's role as the main driver for improving food availability. On the other hand, food accessibility is a dimension directly linked to the economic theory of demand, which mainly focuses on access to sufficient financial resources to support the purchasing power of individuals or households [23, 24].

Evaluating the critical challenges of food accessibility, the following studies [25, 26] highlighted that structural poverty, economic inequality, and continuous food price inflations are the major factors that hinder food accessibility in developing countries, especially those in West Africa. Since food security is not only guaranteed by availability and accessibility, the food utilization dimension is another essential element determining individual food security status. The food consumed needs to provide the best energy required for a healthy life determined by non-food input such as access to clean and safe drinking water and proper environmental sanitation services [21].

According to the FAO, the high rate of global malnutrition, obesity, stunting, and wasting, especially among children, is associated with the poor utility condition of food [21]. Finally, food stability is another critical dimension highlighted in the definition, which focuses on the threat or the risk of food shortage. Generally, examining the factors that influence low domestic agricultural production, the most common ones are conflict, political instabilities, climate change, and natural disasters, forming the most significant threats to the food stability dimension in many nations[27, 28]. Building on the relationship between conflict and food security, the study by [29] concluded that countries with civil unrest directly face food price 
inflation. Generally, the expectation of the sustainable development goals is ending hunger in the entire World by 2030, leaving no one behind", implying that everyone has the fundamental human right to access the required minimum calorie intake per day [30].

\subsection{The current state of food insecurity in West African countries}

In West Africa, the food insecurity situation has continued to attract global policy concern. The recent statistical data published by the Food and Agricultural Organisation in the 2019 report indicated that this region frequently experienced a progressive increase according to most critical food insecurity indicators $[7,8]$. From the data collected, the study presented a more precise descriptive trend analysis showing the current level of food insecurity status in West Africa by using the average value of food production, undernourishment, and severe food insecurity indicators for the period 2014-2018 as a baseline discussion. According to the FAO, these indicators capture the complete measurement required to analyze food insecurity at any level. The average value of food production estimates the net output from each country's economic value from the agricultural sector, which directly justifies the food supply side (availability) that further improves and meets the food demand side (accessibility) at the national level [7].

Table 1. Current Trend of food insecurity in West Africa

\begin{tabular}{|c|c|c|c|c|c|}
\hline Years & $\mathbf{2 0 1 4}$ & $\mathbf{2 0 1 5}$ & $\mathbf{2 0 1 6}$ & $\mathbf{2 0 1 7}$ & $\mathbf{2 0 1 8}$ \\
\hline Average value of food production & 203 & 203 & 204 & 134 & 66 \\
\hline $\begin{array}{c}\text { Prevalence of Undernourishment } \\
\text { (Million) }\end{array}$ & 38,7 & 40,3 & 45 & 53,7 & 56,1 \\
\hline $\begin{array}{c}\text { Severe food insecurity among the } \\
\text { total population (million) }\end{array}$ & 44,4 & 50,9 & 59,6 & 66 & 67,2 \\
\hline
\end{tabular}

Source : FAO food security indicators

Looking at data in (Table 2) above illustrates the low domestic agricultural productivity from each country in West Africa, giving the total average value of food production. The data indicated that in 2014 and 2015, the average value of food production for the 16 countries was constant at a total value of 203; it increases by 1 point in 2016, recording an average of 204, but surprisingly, it decreased to 133 in 2017 and to 66 in 2018. The data suggest that the total agricultural performance in the West Africa region does not indicate much progress in the overall food production system, which affects the food availability and accessibility dimension at the national level. To justify this relationship, between food availability and accessibility the study takes a step further by looking at the prevalence of undernourishment and the total population facing severe food insecurity in the 16 countries. The data form (Table 2) above shows a simultaneous increase in undernourishment and severe food insecurity in the sub-region. In line with previous theories, the study argues that the continuous increase in the prevalence of undernourishment and severe food insecurity can arise from many different socio-economic conditions [7]. These conditions are similar and eminent in the sub-region, such as a high rate of poverty, structural inequality in the distribution of resources, food price inflation, and slow economic growth across many West African countries. However, the low domestic food production is a significant factor for the continued increase in food insecurity in West Africa. Food availability, by definition is the first and most fundamental dimension of food security at any level, which depends on sustainable food production.

Looking at the broader macroeconomic economic level, the study evaluates the GDPPC and the prevalence of undernourishment as comparative analyses for each country to show a clearer picture of the relationship between economic growth and the level of food insecurity. The prevalence of stunting should have been the best option for this evaluation; however, 
since the data is not fully available for each country, the study has turned to the prevalence of the undernourishment indicator.

Table 2. Gross domestic product per capita and prevalence of undernourishment in West African countries

\begin{tabular}{|l|l|l|l|l|l|l|l|l|l|}
\hline \multirow{2}{*}{ Countries } & \multicolumn{2}{|c|}{ GDPPC } & \multicolumn{2}{c|}{$\%$ of PuP } & \multirow{2}{*}{ Country } & \multicolumn{2}{c|}{ GDPPC } & \multicolumn{2}{c|}{ \%PuP } \\
\cline { 2 - 5 } \cline { 8 - 10 } & $\mathbf{2 0 1 7}$ & $\mathbf{2 0 1 8}$ & $\mathbf{2 0 1 7}$ & $\mathbf{2 0 1 8}$ & & $\mathbf{2 0 1 7}$ & $\mathbf{2 0 1 8}$ & $\mathbf{2 0 1 7}$ & $\mathbf{2 0 1 8}$ \\
\hline Benin & 829.4 & 906.5 & 10.1 & 10.1 & Liberia & 453.4 & 437.1 & 38.1 & 372 \\
\hline Burkina Faso & 738.3 & 820.2 & 20 & 20 & Mail & 829.3 & 898.7 & 6 & 6.3 \\
\hline Cape Verde & 3082.2 & 3239.1 & 12.7 & 12.6 & Mauritania & 1526.6 & 1597.8 & 9.6 & 10.4 \\
\hline Cote d'Ivorie & 1570.2 & 1727.6 & 19.6 & 19 & Niger & 497.6 & 520.0 & 14.1 & 15.5 \\
\hline Gambia & 719.8 & 716.5 & 10.2 & 10.2 & Nigeria & 1968.6 & 2153.5 & 11.5 & 13.4 \\
\hline Ghana & 2046.0 & 2224.3 & 5.9 & 5.5 & Senegal & 1235.5 & 1321.1 & 12 & 11.3 \\
\hline Guinea Bissau & 725,4 & 764.8 & 27.4 & 28 & Sierra Leone & 494.8 & 531.3 & 24.4 & 25.6 \\
\hline Guinea & 779.7 & 891.7 & 15.5 & 16.5 & Togo & 594.0 & 646.4 & 16.6 & 16.1 \\
\hline
\end{tabular}

Source: WB/FAO

From table 3 above, it can be noticed that the current GDPPC for each country indicates a slightly increasing trend, except for Gambia and Liberia that recorded a decrease. In theories, countries reporting an increase in the GDPPC are expected to improve socioeconomic conditions and food security. However, comparing the data above, countries like Benin, Guinea Bissau, Burkina Faso, Mali, Mauntaian, Niger, Nigeria, and Sierra Leone with a slight increase in the GDPPC did not truly reflect the national food insecurity. The data shows that, despite the growth of the GDPPC, the undernourishment rate still increased. On the other hand, countries such as Ghana, Cabo Verde, Cote, d'Ivoire, Senegal, and Togo's increase in their GDPPC slightly influence the decreasing rate of undernourishment.

\subsection{The role of agricultural aid in food security}

Theoretically, donor aid (ODA) refers to financial assistance provided to developing countries to improve social and economic development-related issues such as food insecurity and poverty. According to [1], donor aid refers to all the economic values quantified in financial terms and flow from any developed country to developing countries. Donor aid can also be provided in the form of loans or grants disbursed through bilateral or multilateral means to support the development agenda [31]. Empirically, the most recent academic literature that has been published on agricultural aid in developing countries (especially SubSaharan Africa) extensively focused on examining aid effectiveness [9]. Several lines of their findings present similar shreds of evidence and conclusions, namely that agricultural aid to some extent is effective and positive in increasing growth and production output and thus addresses the challenges of food insecurity[9, 10]. Different theories exist in the literature regarding the vital function of agricultural aid in domestic productivity and its contribution to the socio-economic development in Africa. However, none of the literature has examined the direct relationship between development aid to agriculture and food security indicators in West Africa.

The following studies $[9,14]$ concluded that more focus on the sector could sustainably improve the four dimensions of food security and increase the income level of farmers. Several studies have used longitudinal data to examine aid effectiveness in agriculture development, [18] used panel data and the Two-Stage Least Square model (2SLS) to analyze the impact of total foreign aid on agricultural output in 29 low and middle countries in Africa. The result indicates that foreign assistance has a small and positive impact on agricultural production. Growth from agriculture and any other economic sector is a principal determining component of food security. 
Unlike the above evidence, other studies do not generally focus on the direct relationship between agriculture and food security but rather study the determinants and influence factors of food insecurity, such as general social improvement on national services and economic growth, enhancing the utility dimension. [32], analyzing the role of agriculture in poverty reduction, and their findings are noticeable in two critical respects. First, they claim that development in the farming (agricultural) sector is more effective in declining poverty and improving the economic well-being of farmers in rural communities. They justified this claim with empirical evidence indicating that Africa's agricultural productivity growth is 1.6 times better at reducing rural poverty than any other economic growth.

Additionally, their statistical estimation showed that any $1 \%$ increase in the GDP of the agrarian sector relatively decreases the national poverty gap by approximately five times more than the $1 \%$ increase from any other government source. Jiang [33] notes that the agricultural sector in West Africa is the primary driver behind improving national food availability. They emphasize that agriculture's potential attributes will transform so much into local farmers by enhancing their income and domestic food supply. Although, achieving this [4] highlighted the need to break the link of skill barriers and technological gaps between the advanced and developing nations and increase investment, research, education, and subsidies for farmers.

Despite the multiple impacts of the agricultural sector on national development, the following studies [34, 35] indicated that official development assistance, foreign direct investment, and government budget had paid less attention to the sector. According to [35] findings, the decline in donor aid and foreign direct investment in the agrarian sector started in the 1990s. In his results, we discovered that African countries' domestic expenditure on the agricultural sector is less than $10 \%$ of the GDP. Similarly, the research by [15] states that in 2003, the Africa Union leaders agreed for all governments to increase their national budget for the agricultural sector to $10 \%$ of the GDP by 2013; surprisingly, only nine out of fiftyfour (Africa Union) member countries meet the commitment [10].

Together, all these studies believe that to achieve the 2030 agenda nine years from now, the development partners, the private sector, and recipient countries need more proactive collaborative policy effort to foster agriculture development through innovation and modernization of the system, especially in West Africa. Therefore, building the foundation from the theoretical and empirical review of previous studies, this study argues that the flow of aid to the agricultural sector increases domestic food production and consequentially decreases the food insecurity in West Africa. To further strengthen the argument, the following hypotheses have been developed: H1: Agriculture aid has an impact on the average value of food production (availability), H2: Agriculture aid has an impact on decreasing undernourishment (accessibility), H3: Agriculture aid has an impact in improving access to water facility (utilization), and H4: Agriculture aid has an impact on political instability and absence of violence (stability)

\section{Data and methods}

\subsection{Data and variables}

This study uses balanced panel data with annual observations of 16 West African countries between 2009 - 2018. All the data estimated in this study has been collected from the World Bank and FAO. The data for food insecurity indicators and the total development flows disbursed to the recipient's countries has been collected from the FAOSTATA [36]. Food security is an accumulation of different indicators that should be satisfied at all times, reflecting on the complexity of accessing the data. The study selects the indicators of interest 
based on the availability of data. The study examines the average value of food production from the availability; This indicator measures the amount of net food available in market values and the economic size of each country's domestic agricultural production [7]. While the accessibility dimension, the study examines the prevalence of undernourishment which estimated the total number of individuals in a population who lack sufficient calories to maintain a healthy life. In the utilization dimension, the study assessed the percentage of people using basic essential drinking water services, and this indicator is highly significant for explaining the quality of food intake. Finally, from the stability dimension, the study examines political instability and the absence of violence. This indicator measures political shocks that negatively affect domestic agricultural production and national food security [7].

The study uses the total disbursement flows of agricultural assistance in constant 2017 USD for the independent variables. The total disbursement flows have been used because they provide more complete data for the study sample than the various sub-categories of agriculture assistance. The study has included the Gross Domestic Product Per Capita (GDPPC), agricultural value-added/ and domestic food production index as control variables. Furthermore, the study uses control of corruption data from the World Bank development indicators (2019) as an instrumental variable. The control of corruption is measure on a scale between ( -2.5 to 2.5$)$ where -2.5 indicates weak or corrupt government institutions and 2.5 indicates good government institutions (See Table 3 )

Table 3. Summary statistics

\begin{tabular}{|c|c|c|c|c|c|}
\hline Variable & Obs & Mean & S.D & Min & Max \\
\hline Food security indicators & & & & & \\
\hline Average value of food production & 160 & 4.989 & .437 & 3.829 & 5.663 \\
\hline Undernourishment (\% of the population) & 160 & 2.666 & .592 & 1.629 & 4.836 \\
\hline Access to basic clean water services (\%) & 160 & 4.185 & .16 & 3.782 & 4.467 \\
\hline Political instability and absence of violence & 160 & -.87 & 1.223 & -4.605 & .793 \\
\hline Development flow & & & & & \\
\hline $\begin{array}{c}\text { Total agricultural aid (constant price } \\
\text { 2017\$M) }\end{array}$ & 160 & 3.393 & 1.461 & 1.386 & 5.64 \\
\hline Control variables & & & & & \\
\hline Agricultural value-added & 160 & 7.696 & 1.47 & 4.645 & 11.641 \\
\hline Gross domestic per capital (GDPPC) & 160 & 6.864 & .606 & 5.714 & 8.208 \\
\hline Control of corruption & 160 & -.606 & .511 & -1.563 & 1 \\
\hline
\end{tabular}

\subsection{Empirical method}

The study uses the robust instrumental 2SLS approach to analyze agricultural aid on food security indicators. This method has been used because the data on aid effectiveness in the study sample is expected to have an endogeneity problem caused by omitted variables. If not addressed, this could lead to bias coefficient estimation. Based on solid evidence from previous studies $[1,9]$, the Ordinary Least-Square (OLS) seems not to be effective in terms of solving the endogeneity problem. To further strengthen the use of the model and allay these worries of the result, the post estimation test for endogeneity has been applied to determine which best fits the study data, the OLS or 2.SLS

We used STATA version 16.1 and ran first stage regression with aid as the dependent variable followed by the explanatory variables and predicted the residuals (e). In the second stage regression, we ran the main structural equations and included the predicted residuals from the first stage as independent variables. The purpose of this procedure is to test the significant level of the predicted residuals. The empirical result obtained from the second 
stage shows that the predicted residual is significant at $\mathrm{p}=0.000$. At a $95 \%$ confidence level, the study rejects the null hypothesis that the data (variables) are exogenous and concluded the alternative hypothesis indicating that data has an endogeneity problem, which statistically concludes the approach of the 2SLS instrumental method being valid for the data. The structural model for the food security equations is expressed as:

$$
\begin{aligned}
& \ln F S_{\text {it }}=\beta_{0}+\beta_{1} \ln \text { agriaid }_{\text {it }}+\beta_{2} \ln g d p p c_{\text {it }} \\
& +\beta_{3} \text { lnagrivalueadd }_{\mathrm{it}}+\beta_{4} \text { lncorruption }_{\mathrm{it}}+y_{\mathrm{it}}+\varepsilon_{\mathrm{it}}
\end{aligned}
$$

where: $\ln F S_{\text {it }}$ is the food security indicators to be estimated, $\beta$ denote the estimated coefficient of the model, $i$ and $t$ represent the country's and years of observation, while $\varepsilon_{i t}$ denotes the error terms. In agridaid $_{i t}$ represents the total financial aid disbursement flows to recipient

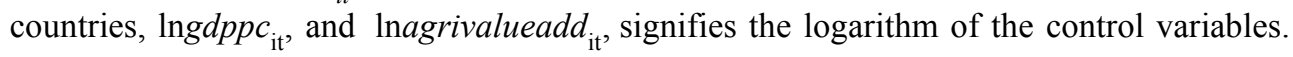
Lastly, the study uses the above structure equation to run the four food security equations.

\section{Result and discussion}

\subsection{The impact of agricultural aid on the food availability dimension}

Theoretically, the first dimension of food security is its availability, which comprises different indicators. This study has estimated the average value of food production indicators. The regression results in Table 4 show that the coefficient of Inagriaid is negatively significant at the $5 \%$ level. The implication of this result suggests that every additional increase in the value of agricultural aid disbursed to West African countries will decrease the average value of food production by $-0.173 \%$. The F statistic for the goodness of fit model is significant $5 \%$ with a $\mathrm{p}=0.000$ for all food security equations. At $95 \%$ confidence level, the study rejects the null and accepts the alternative hypothesis that all the slope coefficients in the model are not jointly equal to zero.

These findings are surprising because agricultural aid is expected to positively impact food availability by increasing the average value of food production. However, there are possible explanations for this result. First, the challenges of different external factors experienced by farmers in the various countries in the sub-region (such as climate change, environmental hazards, and drought) can be primary factors for low domestic agricultural production in West African countries. Moreover, land irrigation is a major problem in the sub-region; most farmers are highly dependent on rainfall for land irrigation, resulting in deficient or limited crop production in the dry season. These implications are somewhat similar to the findings of $[5,7]$, which concluded that these challenges are very eminent among the African countries, which always resulted in deficiencies in the agricultural food production of framers. 
Table 4. The 2SLS regression result

\begin{tabular}{|c|c|c|c|c|}
\hline Variables & $\begin{array}{c}\text { (Availability) } \\
\text { The average } \\
\text { value of food } \\
\text { production }\end{array}$ & $\begin{array}{c}\text { (Accessibility) } \\
\text { \%Prevalence of } \\
\text { undernourishment }\end{array}$ & $\begin{array}{c}\text { (Utilization) } \\
\text { Access to } \\
\text { water } \\
\text { facilities }\end{array}$ & $\begin{array}{c}\text { (Stability) } \\
\text { Political stability } \\
\text { and absence of } \\
\text { violence }\end{array}$ \\
\hline Ln. Agricultural aid & $-0.173^{* * *}$ & $-0.231^{* *}$ & $0.082^{* * *}$ & $-1.318^{* * *}$ \\
\hline & $(0.059)$ & $(0.108)$ & $(0.028)$ & $(0.224)$ \\
\hline $\begin{array}{c}\text { Ln. Agricultural value- } \\
\text { added }\end{array}$ & $0.246^{* * *}$ & 0.126 & $-0.072^{* * *}$ & $0.990^{* * *}$ \\
\hline & $(0.045)$ & $(0.095)$ & $(0.018)$ & $(0.145)$ \\
\hline Ln. GDPPC & -0.047 & $-0.410^{* * *}$ & $0.158^{* * *}$ & -0.081 \\
\hline & $(0.057)$ & $(0.062)$ & $(0.018)$ & $(0.210)$ \\
\hline Ln.corruption & $-0.268^{* * *}$ & $-0.202^{* * *}$ & $-0.174^{* * *}$ & $-0.268^{* * *}$ \\
\hline & $(0.102)$ & $(0.102)$ & $(0.102)$ & $(0.102)$ \\
\hline Constant & $5.225^{* * *}$ & $7.807^{* * *}$ & $4.136^{* * *}$ & $-10.021^{* * *}$ \\
\hline & $(0.764)$ & $(1.041)$ & $(0.226)$ & $(2.107)$ \\
\hline Number of countries & & & & \\
\hline Observations & 16 & 16 & 16 & 16 \\
\hline R-squared & 0.374 & 160 & 160 & 160 \\
\hline
\end{tabular}

Note the Robust standard errors are reported in parentheses

$* * * \mathrm{p}<0.01, * * \mathrm{p}<0.05, * \mathrm{p}<0.1$

Secondly, wrong policies on agriculture support distribution ought to be mentioned. That is to say, the ineffectiveness of government institutions to manage donor funding and the high level of corruption in some recipient countries are other possible factors leading to the inverse relationship. These findings and explanations are reflective of those of $[9,35]$; both studies concluded that the ineffectiveness of government institutions and mismanagement of agricultural aid in most Africa is a possible factor for the decline of agricultural assistance and agricultural production capacity, which negatively influences food security status in the continent. In line with the result, this study argues that since government institutions in West African countries directly receive all donor aid, their institutional qualities and effectiveness in implementing agricultural aid-related projects are significant in improving food availability. The implications of these findings conclude that countries with sound governance systems and strong institutions capacity will build on proactive policies that will improve agricultural performance and productivity to enhance food security at the national. Conversely, the implication of weak governance in executing efficient and effective agricultural policies will decrease domestic food production and negatively influence national food security. Hence, this result could not conceivably support hypothesis 1 , stating that agriculture aid positively impacts the average value of food production (availability).

\subsection{The impact of agricultural aid on food accessibility}

The second dimension of food security is accessibility, where the study analyzes the prevalence of undernourishment indicators. The statistical result in Table 4 shows that the coefficient of lnagriaid is negatively and statistically significant at the $5 \%$ level. The result suggests that every additional increase in value of agricultural flow to West Africa will lead to reductions in the prevalence of undernourishment by -0.231 , holding all other factors constant. We expected to find this result because agriculture aid increases domestic food production and access to the market for framers and increases their income to buy available nutritious food. Additionally, using the purchasing power parity as a proxy for the economic or financial access to food, for example, the lack of sufficient and sustainable income for 
household heads, is one of the driving factors behind the high rate of undernourishment among West African countries.

One possible way to enhance food accessibility in West Africa is by developing the rural communities and improving the socio-economic conditions of the population through adequate policies related to the development of the agricultural sector. In essence, agricultural aid can be utilized as a policy mechanism towards developing the rural agricultural infrastructure such as roads to enhance smooth domestic food supply. Digging more deeply into how agricultural aid improves West Africa's food security by providing subsidies for farmers to expand their agricultural activities and increase their market connectivity. Therefore, an increase in agriculture aid can directly impact job creation in the agriculture sector and improve the working population's income, enabling them to access nutritious food. These implications are in line with [9], who also suggested that an increase in agricultural aid impacts the welfare of the pro-poor in Africa. To conclude the discussion on the findings, the statistical result supports hypothesis 2, stating that agriculture aid decreases undernourishment in West Africa.

\subsection{The impact of agricultural aid on food utilization}

The third most crucial dimension of food security is utilization. Other non-food indicators contribute to the individual food security status. In this study, the indicator of access to clean drinking water facilities has been examined. The regression result in Table 4 indicates that the coefficient of lnagriaid is positively significant at the 5\% level. The result suggests that every additional increase in value of agricultural aid flow to West African countries will increase access to water facilities by 0.082 , thus enhancing food security at the national level. Justifying this result, we argue that one of the fundamental challenges and the causes of malnutrition and other health underlying hazards among the population of most West African countries is lack of access to adequate and better-improved water facilities, especially in rural communities.

Therefore, to explain this result further, it is pertinent that development aid to the agriculture sector, especially those of projects for rural development, can be utilities to construct infrastructure water storage facilities in rural communities to improve the accessibility to clean drinking water. Further, the agricultural aid received can also be directed to water irrigation facilities to increase domestic food production since it is one of the fundamental factors hindering the region's domestic agricultural production. Additionally, these findings can further be deliberated on the sloid premise that an increase in agricultural aid can improve social well-being, promotes economic growth, and significantly reduce poverty and malnutrition in the sub-region. This result provides further support for hypothesis 3, stating that agriculture aid has an impact on improving access to water (utilization).

\subsection{The impact of agricultural aid on food stability}

Food stability is another critical dimension of food security; this has been one factor that hinders the sustainable development agenda. This research has estimated the political instability and absence of violence indicator as a proxy for food insecurity. The regression result in Table 4 above shows that the coefficient of lnagriaid is negatively and statistically significant to food stability, implying that the additional value of total agricultural aid to West Africa will negatively influence food stability by $-1.318 \%$ when analyzed by political instability. Food stability is the foundation of food security, which depends on any country's sustainable and uninterrupted agrarian production system. This result is not surprising when critically analyzing the destabilizing effects of conflict and violence on developing countries' 
domestic agricultural production and food security. The present result is supported by similar findings linking political instability with domestic food production, poverty reduction, and food insecurity in developing countries [28]

The theory has further shown that land conflict and political instability are the critical human factors that negatively interrupt domestic agricultural productivity and food insecurity in most West African countries. For instance, during conflict and political unrest, agricultural activities and production will not function. Most people who engage in agriculture could migrate to other communities, causing a significant decrease in production in the country or region. It is, therefore, theoretically possible and logically conclusive that agricultural aid could not positively influence food production in countries with such challenges, just as in the case of Boko Haram in the Northern part of Nigeria.

Additionally, the high level of inequalities in economic resources distribution and the injustice related to the agricultural land ownership system due to bad governance and corruption systems in West Africa are among other factors that threaten food stability in the sub-region. In this same line of thinking, the finding has demonstrated a strong reserve causality relationship between food stability and availability, indicating that domestic food availability depends on constant domestic agricultural production. Any decrease in agricultural output as a result of these factors will affect food availability in the region. These results provide no further support for hypothesis 4 , stating that agriculture aid has an impact on political instability and absence of violence (stability)

\subsection{The result of the control variable}

The result of the control variables presents different signs. The coefficient of the value-added agricultural variables is significant and positively associated with availability and stability indicators. The statistical result indicates that value-added to agriculture has a long-run multiplier effect on sustainable domestic food production for countries in the study sample. The result suggests that if the government in West Africa pays more attention to the agricultural value-added through modernization and innovation of the systems, it will increase domestic food production. The regression suggested that agricultural value-added can strengthen food availability and stability by $0.246 \%$ and $0.990 \%$, respectively. The findings indicate that agricultural value-added is one practical approach that is aimed at accelerating and improving the short and long-term adverse effects of the West African country's food production systems and agricultural transformation.

The Gross Domestic Production Per Capital (GDPPC) coefficient is negatively significant, with the average value of food production showing a reverse causality on availability. At the same time, the result in accessibility and utilization regression suggests that an increase in national income proves to decrease the prevalence of undernourishment by $-0.149 \%$ and improves access to water facilities by $0.242 \%$. In conclusion, the regression result shows that the coefficient of Incorruption negatively influences all the four food insecurity indicators. These findings further contributed to the significant concern about the control of corruption in West African countries, suggesting that the impact of donor aid on food security is conditional on recipient countries' institutional qualities and level of corruption. The implications of the result indicate that countries with a low score on the government effectiveness index and a high score on corruption are more likely to be food insecure than countries with the opposite scores. These conclusions are in line with several studies on development assistance effectiveness in developing countries [9]. 


\section{Conclusion and recommendation}

This study analyzes the impact of agricultural aid on food availability, accessibility, utilization, and stability of 16 countries in West Africa between 2009-2018 using the 2SLS instrumental approach. The statistical findings indicated that official development aid to the agriculture sector in West African countries has both negative and positive significant impacts on food security indicators. However, these effects vary across the four dimensions based on the indicators analyzed, the recipient countries' institutional qualities, and the level of corruption. This study has shown that agriculture aid to some extent, has a significant role in addressing food insecurity in West Africa.

Generally, based on the data, the study found that the request for official development assistance to improve the agriculture sector is very high within West African countries. However, aid does not have a sustainable long-run effect on food security because of the weak government institution, high levels of corruption in certain countries, and the inconsistency of aid flows. A huge gap will always exist between domestic food production and food security in the sub-region. According to the findings, the study suggests that to narrow the gap, the government across the sub-region should prioritize agriculture valueadded through the technology innovation and modernization of agricultural systems since it has a significant short and long-run multiplier effect in addressing food security.

Acknowledgments: The authors gratefully acknowledge the Government of Indonesia and The Institute for Research and Community Service at Parahyangan Catholic University (LPPM Unpar) for their financial support.

Conflict of interest: The authors declare no conflict of interest.

\section{References}

1. I. Petrikova. Int. J. Dev. Issues. 14, 1 (2015)

2. L. Ehlers, "Curse or Cure? The Relationship Between Food Aid and Food Security in Sub-Saharan Africa: The Cases of Mozambique and Kenya," December, 2019. (2019)

3. K. Pawlak, M. Kołodziejczak. Sustain. 12, 13 (2020)

4. A. Nwozor, J. S. Olanrewaju. Dev. Stud. Res. 7, 1 (2020)

5. United Nations, "The sustainable development goals report 2019," United Nations Publ. issued by Dep. Econ. Soc. Aff., p. 64 [Online]. Available: https://undocs.org/E/2019/68. (2019)

6. S. Vicari, 2014 Annual Report on FAO's projects and activities in support of producer organizations and cooperatives. 2015.

7. FAO. IEEE J. Sel. Top. Appl. Earth Obs. Remote Sens. p. 202 (2019)

8. Food Security Information Network and Global Network Against Crises, "2020 Global Report on Food Crises. Joint analysis for better decisions," Fao.Org, pp. 1-202 [Online]. Available: https://www.wfp.org/publications/2020-global-report-food-crises. (2020)

9. O. Kaya, I. Kaya. Singapore Econ. Rev. 64, 2 (2019)

10. J. Ssozi, S. Asongu, V. H. Amavilah. J. Econ. Stud. 46, 2 (2019)

11. L. Christiaensen, L. Demery, J. Kuhl. The (Evolving) Role of Agriculture in Poverty Reduction, vol. 36. (2010)

12. African Development Bank Group, "Feed Africa: Strategy for transformation in Africa 2016 - 2025," African Dev. Bank Gr., [Online]. Available: https://www.afdb.org/ fileadmin/uploads/afdb/Documents/Policy-Documents/Feed_Africa-Strategy-En.pdf. (2016)

13. C. Nsiah, B. Fayissa, African Dev. Rev. 31, 1 (2019)

14. S. A. Journal, "The Impact Of Foreign Agricultural Aid And Total Foreign Aid On 
Agricultural Output In African Countries : New Evidence From Panel Data Analysis," (2019)

15. A. W. Paper et al. Trade Impact Eur. Union Prefer. Policies,. vol. 1, (2014)

16. R. Haug. "Food security indicators : how to measure and communicate results," no. 83 (2018)

17. L. Hjelm, A. Mathiassen, A. Wadhwa. Food Nutr. Bull., 37, 3 (2016)

18. F. Egal. Review of The State of Food Security and Nutrition in the World, 2019, 10, 3 (2019)

19. D. Banik. Food Ethics, 4, 2 (2019)

20. FAO. Food Security and Nutrition in the World. (2019)

21. FAO. The State of Food and Agriculture. Leveraging Food Systems for Inclusive Rural Transformation, 19, 1 (2017)

22. A. A. Adenle, K. Wedig, H. Azadi. Technol. Soc., 58, no. May (2019)

23. I. Rudolfsen. Terror. Polit. Violence. (2018)

24. H. Yao, M. I. Alhussam, O. A. Risha, B. A. Memon. Sustain., 12, 7 (2020)

25. R. Mahadevan, V. Hoang. Soc. Indic. Res., 128, 1 (2016)

26. A. Gassner et al. Outlook Agric., 48, 4 (2019)

27. M. West, T. M. Mashizha, C. Ncube, A. Dzvimbo, M. Monga. "Examining the Impact of Climate Change on Rural Livelihoods and Food Security : Evidence From Sanyati District in," 3, 2 (2017)

28. B. James Deaton, B. Lipka. J. Food Secur., 3, 1 (2015)

29. S. van Weezel. Oxf. Econ. Pap., 68, 3 (2016)

30. M. Leach, Gender equality and sustainable development. (2015)

31. OECD/FAO. OECD-FAO Agric. Outlook 2016-2025, 181, November (2016)

32. L. Christiaensen, L. Demery, J. Kühl. World Bank Res. Obs., June (2014)

33. X. Jiang, Y. Chen. "The Potential of Absorbing Foreign Agricultural Investment to Improve Food Security in Developing Countries," (2020)

34. J. Ssozi, S. Asongu, V. H. Amavilah. Journal of Economic Studies Article information, March (2019)

35. N. Islam, "Foreign aid to agriculture: Review of facts and analysis," January, 2011. [Online]. Available: http://www.ifpri.org/sites/default/files/publications/ifpridp01053 .pdf. (2011) 